2011-07-05

The face inhibition effect: Social contrast or motor competition?

Tipper, SP

http://hdl.handle.net/10026.1/1013

10.1080/20445911.2011.451888

Journal of Cognitive Psychology

All content in PEARL is protected by copyright law. Author manuscripts are made available in accordance with publisher policies. Please cite only the published version using the details provided on the item record or document. In the absence of an open licence (e.g. Creative Commons), permissions for further reuse of content should be sought from the publisher or author. 
This article was downloaded by: [Univ of Plymouth]

On: 28 March 2012, At: 06:48

Publisher: Psychology Press

Informa Ltd Registered in England and Wales Registered Number: 1072954 Registered office: Mortimer House, 37-41 Mortimer Street, London W1T 3J H, UK

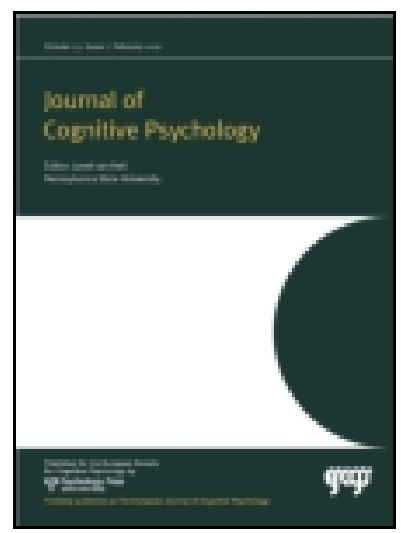

\section{J ournal of Cognitive Psychology}

Publication details, including instructions for authors and subscription information: http:// www.tandfonline.com/loi/ pecp21

\section{The face inhibition effect: Social contrast or motor competition?}

Steven P. Tipper ${ }^{a} \&$ Patric Bach ${ }^{a}$

${ }^{a}$ Centre for Clinical and Cognitive Neuroscience, University of Wales, Bangor, UK Available online: 08 Feb 2011

To cite this article: Steven P. Tipper \& Patric Bach (2011): The face inhibition effect: Social contrast or motor competition?, J ournal of Cognitive Psychology, 23:1, 45-51

To link to this article: http:// dx.doi.org/ 10.1080/20445911.2011.451888

\section{PLEASE SCROLL DOWN FOR ARTICLE}

Full terms and conditions of use: http://www.tandfonline.com/page/terms-and-conditions

This article may be used for research, teaching, and private study purposes. Any substantial or systematic reproduction, redistribution, reselling, loan, sub-licensing, systematic supply, or distribution in any form to anyone is expressly forbidden.

The publisher does not give any warranty express or implied or make any representation that the contents will be complete or accurate or up to date. The accuracy of any instructions, formulae, and drug doses should be independently verified with primary sources. The publisher shall not be liable for any loss, actions, claims, proceedings, demand, or costs or damages whatsoever or howsoever caused arising directly or indirectly in connection with or arising out of the use of this material. 


\title{
The face inhibition effect: Social contrast or motor competition?
}

\author{
Steven P. Tipper and Patric Bach \\ Centre for Clinical and Cognitive Neuroscience, University of Wales, Bangor, UK
}

\begin{abstract}
Merely viewing the faces of famous athletes affects the observers' motor system, suggesting that actionbased information is a core feature of person representations, even when no specific action is visible (Bach \& Tipper, 2006). Unexpectedly, these person-based motor priming effects were inhibitory. Foot responses were slower when identifying footballers, and hand responses for tennis players. Here, we demonstrate that these inhibitory effects are only evoked when action is implicitly associated with the athletes; when the athletes are seen performing their skilled actions the effect reverses towards facilitation. The contrast between inhibition evoked by implicit action priming and facilitation evoked by the explicit presentation of an action supports the notion of inhibitory control in the motor system. We hypothesise that when no specific action is perceived, a range of actions are activated triggering lateral inhibition, whereas when a specific action is viewed, there is no competition and excitation facilitates similar responses.
\end{abstract}

Keywords: Embodied cognition; Inhibition; Motor priming; Person memory; Social perception.

Research has demonstrated that the motor system not only subserves the output of goal-directed behaviour, but is also involved in representing the actions of others. So-called "mirror neurons" have been discovered in the premotor cortex of the macaque monkey (di Pellegrino, Fadiga, Fogassi, Gallese, \& Rizzolatti, 1992). Mirror neurons fire not only if a monkey performs a particular action, but also if it sees this action being performed by a conspecific, suggesting that others' actions are coded in the same way as our own. In humans, mirror-like processes have been demonstrated by studies showing overlapping brain activation during both action execution and observation (e.g., Buccino, Binkofski, Fink, Fadiga, Fogassi, et al., 2001; Chong, Cunnington, Williams, Kanwisher, \& Mattingley, 2008). Moreover, behavioural studies have repeatedly demonstrated that observing an action facilitates the production of similar actions but interferes with the production of different actions (e.g., Brass, Bekkering, Wohlschläger, \& Prinz, 2000). For instance, seeing a video of a person kick a football facilitates foot responses relative to finger responses, and vice versa for seeing a person typing on a keyboard (Bach, Peatfield, \& Tipper, 2007; Bach \& Tipper, 2007).

It has been proposed that such "embodied" representations of others' actions could provide an observer with empathic insights into how the actions would feel for the other person, allowing inferences about the internal states driving them (Barsalou, Niedenthal, Barbey, \& Ruppert, 2003; Gallese, 2001; Hayes, Paul, Beuger, \& Tipper, 2007; Tipper \& Bach, 2008). A crucial question is, however, whether such processes only help us to understand actions that are directly observed, or whether they also allow us to put ourselves in the

Correspondence should be addressed to Patric Bach, School of Psychology, University of Plymouth, Drake Circus, Plymouth PL4 8AA, UK. E-mail: patric.bach@plymouth.ac.uk

The work was supported by a Wellcome Trust Programme grant awarded to SPT.

(C) 2011 Psychology Press, an imprint of the Taylor \& Francis Group, an Informa business http://www.psypress.com/ecp 
shoes of others, when they are not acting. Such a role would significantly broaden the ways in which embodiment processes could guide social interactions, adding to the action understanding processes that occur ex post, the possibility of anticipating other people's motor behaviours that are not yet performed (e.g., Liepelt et al., 2009).

Consider the situation of observing the face of Wayne Rooney (the famous English footballer). A central aspect to the representation of this person should be expert motor skills with the feet, predicting activation of foot-related motor representations in the observer. In contrast, when viewing the face of a famous tennis player such as Tim Henman, embodiment accounts of person perception predict activation of this individual's expert hand skills. Such person-based motor priming effects have indeed been demonstrated (Bach \& Tipper, 2006) when viewing the faces of such famous tennis and footballers, even though the stimuli did not contain any cues to these persons' motor skills. Intriguingly, however, these motor priming effects were inhibitory: Responses with the body part (hands or feet) involved in the viewed athlete's sport were slower and less accurate.

Here, we test two accounts of these unexpected inhibitory priming effects. The first account was proposed by Bach and Tipper (2006) in an attempt to explain the face inhibition effects. Within social psychology it is well established that priming participants with a trait (e.g., intelligence) via a person with very high values on this trait (e.g., Albert Einstein) inhibits performance on related tests (i.e., knowledge tests; Bargh, Chen, \& Burrows, 1996; Dijksterhuis et al., 1998). It is assumed that such contrast effects occur because participants automatically compare themselves with the primed individuals. When they find their abilities to be inferior, performance on related tasks is impaired. Since the athletes in our study possessed very elite motor skills, beyond the skills attainable by our student participants, the inhibitory priming effects could arise from such quick and automatic social comparisons.

However, in contrast, the inhibitory effects may reflect a more basic mechanism in the motor system. For coherent goal-directed behaviour it is crucial that a specific action is evoked at a specific point in time, while other less desirable actions are prevented from being carried out. Models of the motor system therefore include inhibitory mechanisms that hold inappropriate responses at bay. In the model of Houghton and Tipper (1994), for instance, lateral inhibition acts on simultaneously activated motor schemata that lower the overall response tendencies, until one motor schema is activated over and above the others. Such models predict that for a visual stimulus to facilitate a response, this stimulus needs to strongly prime one specific motor response, rather than a whole set of similar responses that may inhibit one another. Indeed, an increasing number of studies recently reported negative motor priming effects when motor responses were primed in a perceptually weak and/or unspecific manner (e.g., Schlaghecken \& Eimer, 2002; Sumner, Pei-Chun, Yu, \& Nachev, 2006). Therefore, because the face of an athlete can similarly only weakly prime a whole range of motor behaviours associated with the athletes' sport rather than one specific action (i.e., not a specific kick, but all the highly skilled foot behaviours associated with football), the inhibitory effects could reflect such automatic inhibition processes.

To differentiate between the two accounts of the inhibitory motor priming effects, we used a task in which participants identified two famous footballers and tennis players with finger and foot keypresses. Of each type of athlete (tennis, football), one always had to be identified with a finger keypress and the other with a foot keypress, creating a situation in which each response (finger, foot) was either compatible or incompatible with the identified athlete's sport (tennis, football). Crucially, in one condition, only the athletes' face was visible, with no information as to their sport being present. This nonaction condition is compared to a condition where the athletes are shown performing their highly skilled motor behaviours (i.e. kicking a football, or hitting a tennis ball with a racket). This manipulation keeps the perceived motor skills of the athletes constant, but varies whether the stimuli weakly/implicitly primed a diffuse range of motor behaviours associated with the athletes' sports (the nonaction face images) or directly/explicitly primed a very specific motor action out of this range (the action images).

If the inhibitory effects emerged due to automatic social comparison processes, then we predict inhibition effects in both conditions, because the same highly skilled athletes were presentand had to be identified - in both types of images. If, however, the effects emerged because the nonaction face stimuli were too weak and general 
to prime specific actions, the inhibition effects should turn into facilitation effects when the athletes are shown performing their sports and specific motor behaviours are activated strongly and specifically (i.e., a particular way of kicking the football). Note that this latter prediction of facilitation effects for the action images is not trivial, as such effects are not detected when seeing nonfamous individuals in static pictures, even when performing an action on an object, such as kicking a football (Bach et al., 2007; Bach \& Tipper, 2007). Hence the first detection of such facilitation effects in these Action conditions would reflect the retrieval of the skilled motor representations of the famous athlete.

\section{METHOD}

\section{Participants}

Forty-eight students (11 males) ranging in age from 18 to 29 years participated in the study. All participants were students at Bangor University, Wales. All had normal or corrected-to-normal vision. They received payment for their participation (£5) and gave informed consent. The study was approved by Bangor University's Ethics committee and was conducted in accordance with the Declaration of Helsinki. Subjects were

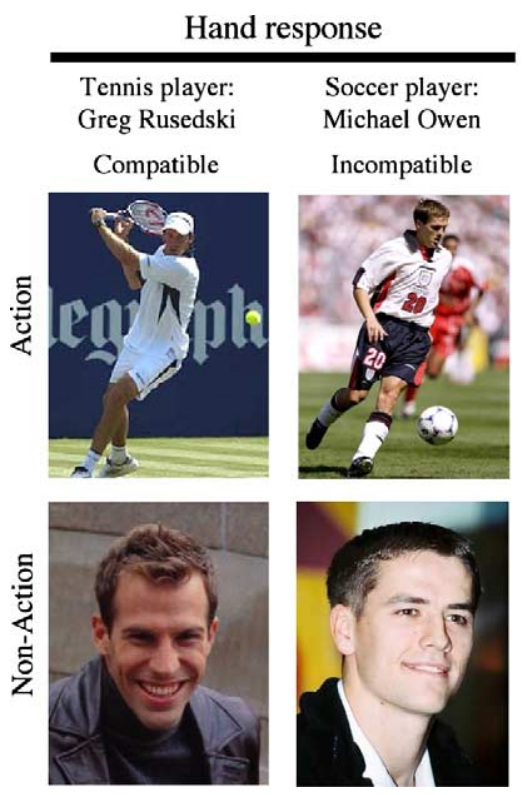

only allowed to participate after confirming on a questionnaire that they knew each athlete either from reading about him or from watching him play. Four additional participants that made more than $20 \%$ errors in total were excluded.

\section{Material and apparatus}

The experiment was controlled by Presentation run on a $3.2 \mathrm{GHz}$ PC running Windows XP. Ninety-six pictures made up the stimulus set. Equal numbers of these pictures were photographs of Wayne Rooney, Michael Owen, Greg Rusedski, and Tim Henman (24 photographs each). One half of these photographs showed the athletes during nonsporting activities (nonaction stimuli, Figure 1, lower panels). The other half showed the athletes on the football field or the tennis court, performing their typical motor behaviours with the corresponding goal objects (i.e., kicking a football, or hitting a tennis ball with a racket) (action stimuli, Figure 1, upper panels).

\section{Procedure and design}

The participants were seated in a dimly lit room facing a colour monitor at a distance of $60 \mathrm{~cm}$.

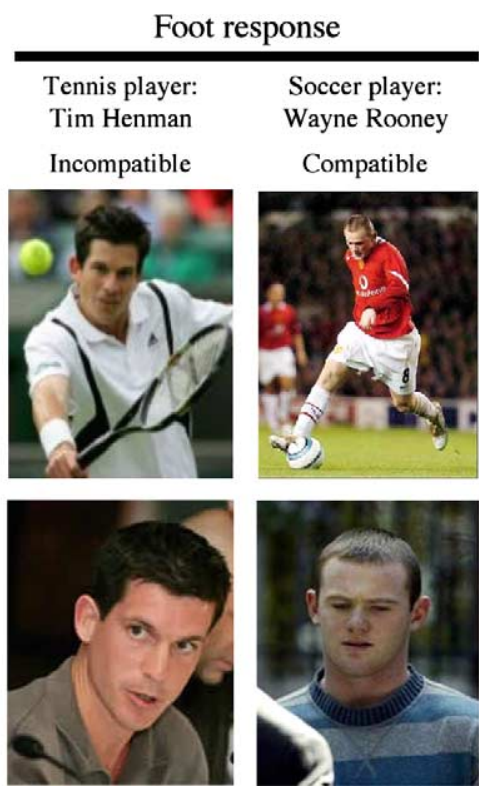

Figure 1. Example key assignment. This participant has to identify the tennis player Greg Rusedski and the footballer Michael Owen with a hand response, and the tennis player Tim Henman and the footballer Wayne Rooney with a foot response. The upper row shows example images of the athletes in their typical environment performing their sports (action condition) and the lower row shows example images of the athletes in everyday situations, not performing their typical motor behaviours (nonaction condition). 
They filled out a sheet that asked them how often they had seen the athletes play their sport and how often they had read about them (1-5 scale, anchored as "not at all" on the one end and "very often" on the other). The participants then received a computer-driven instruction and their response assignment. For each participant, one tennis player had to be identified with a finger key (compatible) and the other tennis player with a foot key (incompatible). Analogously, one footballer had to be identified with a foot response (compatible) and the other with a finger response (incompatible). This assignment of athletes to response keys was counterbalanced across participants. Participants performed a short training phase after which the experiment proper started. It lasted for about 20 minutes and consisted of four blocks of 96 trials each. In each block, all images appeared once in a randomised order. Thus, in one half of the trials the athletes had to be identified with a compatible response (hand response for tennis players, foot response for footballers), and in the other half they had to be identified with an incompatible response.

The course of each trial was as follows: After the participants initiated the trial by pressing the space bar with their left hand, the photograph of the athlete was presented after $500 \mathrm{~ms}$. They identified the athlete by either pressing the foot pedal with their right foot or the enter button on the computer keyboard with their right index finger. Participants were instructed to give their judgement in the interval in which this photograph was on the screen $(1500 \mathrm{~ms}$.). If their judgement was correct, the next trial started. If they made an error or did not react in the given response interval of $1500 \mathrm{~ms}$, an error-message was displayed.

After the experiment was finished, a computerbased questionnaire assessing the participants' views of the athletes' level of skill was administered, by using the numerical keys on the computer keyboard to enter a value ranging from -4 to +4 (anchored with "not at all" on one side and "very much" on the other). For each of the athletes, the participants assessed how skilled they judged him to be at his own sport compared to other professional athletes (e.g., football for Wayne Rooney, tennis for Tim Henman), how talented they thought the athlete would be for the respective other sport (e.g., tennis for Wayne Rooney, football for Tim Henman), and how much they generally liked him.

\section{RESULTS}

\section{Compatibility effects}

For the analysis of RTs (Figure 2, top panel), trials in which the participants pressed the wrong button or did not react in the given time interval were excluded $(8 \%)$. The remaining RTs were entered into a repeated-measures ANOVA with the within-subjects factors compatibility (compatible/incompatible) and context (action/nonaction). There was a main effect of context, $F(1,47)=354.8, \quad p<.001, \quad M S E=576.23$. The athletes were identified more quickly when they were seen at everyday activities than when seen performing their sports, probably because the tobe-identified faces were larger/clearer in the former images. The main effect of compatibility was not significant $(F<1)$, but there was a highly significant interaction of context and compatibility, $F(1,47)=21.4, p<.001, M S E=555.29$. Post hoc $t$-tests showed that when the athletes were shown performing their sport in the action condition, responses were faster $(p=.016)$ when the sporting activity was similar to the identification response (foot-football, hand-tennis). When, however, the athletes were presented not performing an action in the nonaction condition, the data showed that responses similar to the athletes' skilled effector were impaired $(p<.033)$.

The error rates were analysed with the same ANOVA model. As in the analysis of RTs, there was a main effect of context, $F(1,47)=90.3$, $p<.001, M S E=.001$, but neither the main effect of compatibility $(F<1)$, nor the interaction of compatibility and context, $F(1,47)=1.4, p=.25$, $M S E=.001$, were significant. Numerically, the data pattern resembled the RT data (Figure 2, lower panel).

\section{Correlations with subjective ratings}

To ascertain how far the observed effects depend on the participant's prior knowledge of and attitude towards the athletes, we ran separate regression analyses with the participants' average compatibility effects in the action and nonaction condition for the RTs and error rates as criterion variables and the participants' familiarity with the athletes (from seeing them play and reading about them) and their ratings of the athletes' skill in the athletes' own sport (e.g., football for 

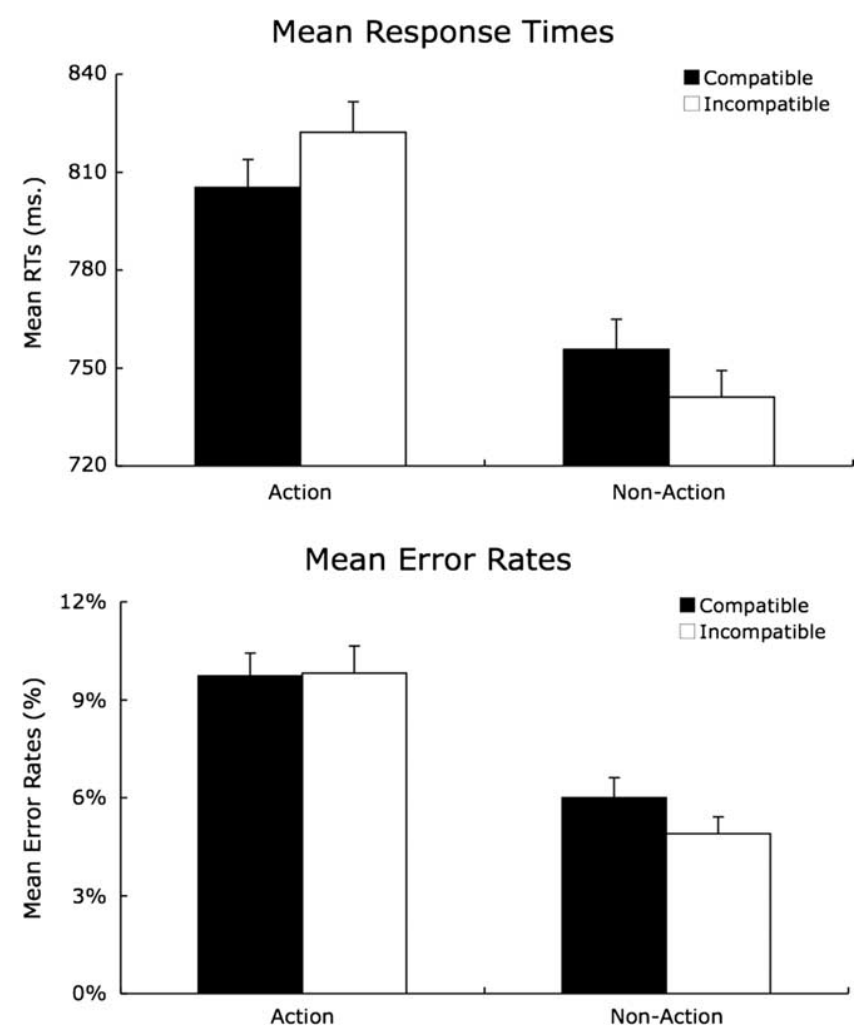

Figure 2. Mean RTs (upper panel) and mean error rates (lower panel). The error bars show the standard error of the mean.

Wayne Rooney), the respective other sport (e.g., tennis for Wayne Rooney), and the participants' general liking of the athletes, as predictor variables. Table 1 shows the results of this analysis for the RTs and error rates, for both the action and nonaction conditions. In the action condition, the compatibility effects showed, first, significant relationships with the participants' subjective judgements of the athletes. Motor priming effects were stronger for those participants who judged the athletes to be highly skilled at their own sport (e.g., football for Wayne Rooney), whereas no relationships were apparent with their perceived skill in the respective other sport (e.g., tennis for Wayne Rooney), nor with the participants' general liking of the athletes. In addition, the compatibility effects in the RTs of the action conditions were also significantly determined by how often the participants' had previously watched the athletes perform their sport, whereas the amount they read about them had no effect. These relationships were only found in the action condition where the athletes were viewed performing their skilled actions. In the nonaction condition, no significant relationships were observed.

TABLE 1

Results of the regression analysis, showing the standardised beta coefficients describing the relationships between motor priming effects in both the action and nonaction conditions for RTs and error rates and the respective predictor variables

\begin{tabular}{|c|c|c|c|c|}
\hline \multirow[b]{2}{*}{ Predictor } & \multicolumn{2}{|c|}{ Action } & \multicolumn{2}{|c|}{ Nonaction } \\
\hline & $\Delta R T s$ & $\Delta$ Errors & $\Delta R T s$ & $\Delta$ Errors \\
\hline Familiarity: Seen play & $.33 *$ & .13 & .00 & .09 \\
\hline Familiarity: Read about & -.25 & .01 & .05 & -.28 \\
\hline Skill: Athlete's sport & $.41 * *$ & $.43 * *$ & .21 & .00 \\
\hline Skill: Other sport & -.12 & .05 & -.12 & -.24 \\
\hline Liking & -.07 & -.11 & -.04 & .16 \\
\hline
\end{tabular}

$$
* p<.05, * * p<.01 \text {. }
$$




\section{DISCUSSION}

Identifying famous athletes automatically activates the motor system. The resulting motor priming effects can be either facilitatory or inhibitory, depending on the situation in which the athletes are observed. Viewing the athlete's face without direct cues to action leads to an inhibition of responses similar to the athletes' sport (e.g., foot responses are slowed when identifying the face of a footballer). However, when the athletes are seen producing a specific example of their skilled behaviour (e.g., kicking a football or hitting a tennis ball with a racket), clear motor facilitation effects were observed, and responses similar to the athlete's sporting activity were sped up. Furthermore, in the latter action condition at least, larger facilitation priming effects were produced by those participants who had observed the athletes play their sport more often and who rated the athletes as more highly skilled.

This pattern of results differentiates between the two theories proposed to explain the inhibition effects when identifying the face of an athlete in the nonaction condition. In terms of the social contrast account, we had previously assumed that the inhibitory motor priming effects emerged because people automatically compare themselves with others, and map the outcome of these comparisons - being less skilled than Wayne Rooney in using one's feet, for example - onto their motor system (Dijksterhuis et al., 1998). Such views predict, however, that motor inhibition would also occur when the athletes are presented while performing their sport. Indeed, this account might predict that the contrast between participant and athlete skill level would be greater when observing a specific example of the skill, particularly when the participant has had many previous exposures to the skill via observation of the athletes, and rates them as highly skilled. However, the opposite pattern of results was observed, with the action condition showing motor facilitation that was stronger when the participant rated the athletes as more highly skilled.

Thus, motor priming is better predicted by current models of the motor system that postulate that action stimuli have to be salient and specific to facilitate overt motor behaviour, whereas nonspecific action stimuli, or those that lack salience due to masking, cause inhibition (e.g., Eimer \&
Schlaghecken, 2003; Houghton \& Tipper, 1994). In the model of Houghton and Tipper (1994), for example, lateral inhibition acts between different, simultaneously activated motor actions, which may lower the overall response tendencies for this group of actions, unless one motor schema is activated strongly and specifically enough to establish itself against all the others (see also, Dagenbach \& Carr, 1994). Consistently, recent studies reporting negative compatibility effects have all used stimuli that did not show the target behaviour directly but primed it implicitly, for instance by using subliminal presentation (Eimer \& Schlaghecken, 2003) or language cues for actions that involve a set of different motor behaviours rather than a specific one (e.g., "sowing the shirt"; Buccino et al., 2005). Analogously, we propose that the faces of the athletes activate a whole class of motor skills associated with the athlete in a weak and nonspecific manner (i.e., all motor acts associated with football or tennis), and therefore give rise to the observed inhibition effects. If, however, the stimuli provide strong visual evidence for specific motor behaviours in the action condition (i.e., a certain way of attacking the ball with the tennis racket), the corresponding responses of the observer can become facilitated.

Interestingly, these motor priming effects were greater when the participant has learned about the athletes' motor skill via observation, and rated the athletes' skill level highly. That the effects in the action condition are driven by knowledge about the athletes' high level of skill is further supported by contrasts of our new data with previous research. When, in similar studies, nonfamiliar individuals are seen or identified in static images without apparent motion, no motor priming effects are detected even when motor acts on specific objects, such as kicking a ball, are observed, or when passive individuals are presented next to objects that are typically manipulated by either feet or hands (Bach et al., 2007; Bach \& Tipper, 2007). This indicates that what contributes to the motor priming effects in the action condition are neither the observed motor acts or objects alone, but the specific visuomotor memories derived from observing the athletes perform highly skilled motor behaviours, as reflected in the correlation with prior viewing of the athletes skilled behaviour (as opposed to reading about them). We therefore suggest that only when the individual identified has known high skill levels in the motor domain, 
can facilitation be detected for actions displayed in static images. In contrast, when the observed behaviour does not closely match the participant's prior experiences with the athletes in the nonaction condition, these relationships are not observed, and similar motor performance is inhibited.

\section{CONCLUSIONS}

Our new data anchor the embodiment of action in models of the motor system which contain a number of properties. First, behaviour is shaped by both excitation and inhibition processes. The subtle interactions between these two types of feedback systems determine the level of activation internal representations achieve, resulting in a range of effects from facilitatory to inhibitory priming, just as described here and in other studies of motor priming. Second, the action priming effects not only reflect basic visuomotor processes transforming observed actions into one's own action tendencies. On the contrary, deeper levels of semantic prior knowledge about a famous athletes' skill, and visuomotor memories of their actions, influence motor states.

Original manuscript received September 2009 Revised manuscript received November 2009

\section{REFERENCES}

Bach, P., Peatfield, N. A., \& Tipper, S. P. (2007). Focusing on body sites: The role of spatial attention in action perception. Experimental Brain Research, 178, 509-517.

Bach, P., \& Tipper, S. P. (2006). Bend it like Beckham: Embodying the motor skills of famous athletes. Quarterly Journal of Experimental Psychology, 59, 2033-2039.

Bach, P., \& Tipper, S. P. (2007). Implicit action encoding influences personal-trait judgments. Cognition, 102, 151-178.

Bargh, J. A., Chen, M., \& Burrows, L. (1996). Automaticity of social behavior: Direct effects of trait construct and stereotype activation on action. Journal of Personality and Social Psychology, 71, 230244.

Barsalou, L. W., Niedenthal, P. M., Barbey, A., \& Ruppert, J. (2003). Social embodiment. In B. Ross (Ed.), The psychology of learning and motivation (Vol. 43, pp. 43-92). San Diego, CA: Academic Press.

Brass, M., Bekkering, H., Wohlschläger, A., \& Prinz, W. (2000). Compatibility between observed and executed finger movements: Comparing symbolic, spatial and imitative cues. Brain and Cognition, 44, 124-143.

Buccino, G., Binkofski, F., Fink, G. R., Fadiga, L., Fogassi, L., \& Gallese, V. (2001). Action observation activates premotor and parietal areas in a somatotopic manner: An fMRI study. European Journal of Neuroscience, 13, 400-404.

Buccino, G., Riggio, L., Melli, G., Binkofski, F., Gallese, V., \& Rizzolatti, G. (2005). Listening to actionrelated sentences modulates the activity of the motor system: A combined TMS and behavioral study. Cognitive Brain Research, 24(3), 355-363.

Chong, T., Cunnington, R., Williams, M., Kanwisher, N., \& Mattingley, J. (2008). fMRI adaptation reveals mirror neurons in human inferior parietal cortex. Current Biology, 18(20), 1576-1580.

Dagenbach, D., \& Carr, T. H. (1994). Inhibitory processes in perceptual recognition: Evidence for a center-surround attentional mechanism. In D. Dagenbach \& T. H. Carr (Eds.), Inhibitory processes in attention, memory and language (pp. 227-358). San Diego, CA: Academic Press.

Dijksterhuis, A., Spears, R., Postmes, T., Stapel, D. A., Kroomen, W., \& van Knippenberg, A. (1998). Seeing one thing and doing another: Contrast effects in automatic behavior. Journal of Personality and Social Psychology, 75, 862-871.

Di Pellegrino, G., Fadiga, L., Fogassi, L., Gallese, V., \& Rizzolatti, G. (1992). Understanding motor events: A neurophysiological study. Experimental Brain Research, 91, 176-189.

Eimer, M., \& Schlaghecken, F. (2003). Response facilitation and inhibition in subliminal priming. Biological Psychology, 64, 7-26.

Gallese, V. (2001). The "shared manifold" hypothesis: From mirror neurons to empathy. Journal of Consciousness Studies, 8(5-7), 33-50.

Hayes, A. E., Paul, M. A., Beuger, B., \& Tipper, S. P. (2008). Self produced and observed actions influence emotion: The roles of action fluency and eye gaze. Psychological Research, 72, 461-472.

Houghton, G., \& Tipper, S. P. (1994). A model of inhibitory mechanisms in selective attention. In D. Dagenbach \& T. H. Carr (Eds.), Inhibitory processes in attention, memory, and language (pp. 53-112). San Diego, CA: Academic Press.

Liepelt, R., Ullsperger, M., Obst, K., Spengler, S., von Cramon, D. Y., \& Brass, M. (2009). Contextual movement constraints of others modulate motor preparation in the observer. Neuropsychologia, 47(1), 268-275.

Schlaghecken, F., \& Eimer, M. (2002). Motor activation with and without inhibition: Evidence for a threshold mechanism in motor control. Perception and Psychophysics, 64, 148-162.

Sumner, P., Pei-Chun, T., Yu, K., \& Nachev, P. (2006). Attentional modulation of sensorimotor processes in the absence of perceptual awareness. Proceedings of the National Academy of Science. USA, 103(27), 10520-10525.

Tipper, S. P., \& Bach, P. (2008). Your own actions influence how you perceive other persons: A misattribution of action appraisals. Journal of Experimental Social Psychology, 44(4), 1082-1090. 